\title{
A Fluorine-19 NMR Study of the Microstructure of Vinylidene Fluoride-Trifluoroethylene Copolymers
}

\author{
Toshiharu YAGI and Masayoshi TATEMOTO \\ Daikin Kogyo Co., Ltd., Application Research Department, \\ Chemical Division, 700-1, Hitotsuya, Settsu-shi, Osaka 564, Japan.
}

(Received July 18, 1978)

\begin{abstract}
Copolymers of vinylidene fluoride (VDF) and trifluoroethylene (TRFE) covering the whole range of copolymer compositions were prepared by the bulk-polymerization method using a peroxide as initiator. The monomer reactivity ratios were $r_{\mathrm{A}}(\mathrm{VDF})=0.7$ and $r_{\mathrm{B}}$ (TRFE) $=0.5$. The microstructure of the copolymers was examined by high-resolution ${ }^{19} \mathrm{~F}$ NMR. The normalized monomer-diad and -triad fractions as a function of polymer composition were obtained from NMR line-intensity relationships and numerical calculations using the comonomer-sequence distribution theory suggested by Ito and Yamashita. It was found that the VDF-TRFE copolymer has a statistically random configuration, and the head-to-tail structures of VDF-TRFE or TRFE-VDF sequences are predominant.
\end{abstract}

KEY WORDS Vinylidene Fluoride-Trifluoroethylene Copolymer / Monomer Reactivity Ratio / Sequence Distribution / Fluorine-19 NMR / Microstructure /

Microstructure and comonomer-sequence distribution are of central importance in the study of copolymerization. It has been shown by many authors ${ }^{1-15}$ that ${ }^{19} \mathrm{~F}$ NMR is very useful for studying the microstructure of fluorine containing homopolymers and copolymers, since the fluorine chemical shifts are so large compared with those of proton. On the other hand, theories to characterize the comonomer-sequence distribution in copolymer have been given by many authors, ${ }^{16-28}$ all of whom applied a stationary process.

By using $56.45 \mathrm{MHz}$ magnetic-field strength NMR, we can study the presence of the carbonpentad sequence (one containing 5 carbon atoms along the polymer chain) in the $-\mathrm{CF}_{2}-$ region. In a previous paper, ${ }^{15}$ we dealt with the microstructure of poly(trifluoroethylene) (PTRFE) with regard to the head-to-tail (H-T), head-to-head (H-H), tail-to-tail (T-T), and tail-to-head (T-H) structures using ${ }^{19} \mathrm{~F}$ NMR and a Monte Carlo simulation, and found that the amount of the normal $\mathrm{H}-\mathrm{T}$ structures is very small in a polymer chain.

The purposes of this study are, first, to examine the microstructure of vinylidene fluoride (VDF)trifluoroethylene (TRFE) copolymers by ${ }^{19} \mathrm{~F}$ NMR, and second, to obtain the normalized monomer-diad and -triad fractions as a function of polymer composition from NMR line-intensity relationships and numerical calculations using the comonomersequence distribution theory suggested by Ito and Yamashita. ${ }^{27}$

\section{EXPERIMENTAL}

\section{Materials}

VDF-TRFE copolymers were prepared in bulk polymerization at $22^{\circ} \mathrm{C}$ using 3,5,6-trichloroperfluorohexanoyl peroxide as initiator.

The polymerization was stopped at a low con-

Table I. Copolymerization of vinylidene fluoride (VDF) with trifluoroethylene (TRFE)

\begin{tabular}{cccc}
\hline $\begin{array}{c}\text { Sample } \\
\text { no. }\end{array}$ & $\begin{array}{c}\text { TRFE mol\% } \\
\text { in monomer }\end{array}$ & $\begin{array}{c}\text { TRFE mol\% } \\
\text { in polymer }\end{array}$ & $\begin{array}{c}\text { Melting } \\
\text { point, }{ }^{\circ} \mathrm{C}\end{array}$ \\
\hline A1 & 0 & 0 & 175.8 \\
A2 & 8.0 & 10 & 146.7 \\
A3 & 12.5 & 15 & 149.7 \\
A4 & 40.0 & 40 & 155.2 \\
A5 & 60.5 & 55 & 163.8 \\
A6 & 72.5 & 64 & 165.7 \\
A7 & 100.0 & 100 & 199.4 \\
\hline
\end{tabular}


version, under $20 \%$, so as to estimate the polymer composition. The monomer composition of these copolymers was determined by carbon element analysis. The results are summarized in Table I. These copolymers are soluble in many kinds of solvents and are in the crystalline state over the whole range of copolymer compositions. Melting points are also listed in Table I.

\section{Measurements}

Carbon analysis was undertaken with a YANACO C,H,N-CORDER, Type-2.

Thermal analysis was performed with a PerkinElmer DSC-2 differential scanning calorimeter at a heating rate of $10^{\circ} \mathrm{C} / \mathrm{min}$. Aluminium pans were used as sample containers and each specimen weight was $10 \mathrm{mg}$.

High resolution ${ }^{19} \mathrm{~F}$ NMR spectra were measured with a Hitachi-Perkin-Elmer R-20B spectrometer at $35^{\circ} \mathrm{C}$ in $N, N$-dimethylformamide for PVDF and in acetone for PTRFE and VDF-TRFE copolymers, using $\alpha, \alpha, \alpha$-trifluorotoluene (BTF) as the internal reference.

\section{RESULTS AND DISCUSSION}

\section{Monomer-Reactivity Ratio}

Figure 1 shows the monomer-polymer composition diagram of the VDF-TRFE copolymer system taken from Table I. We obtained the monomer reactivity ratios from the copolymer compositions using the Fineman and Ross $\operatorname{method}^{29}: r_{\mathrm{A}}$

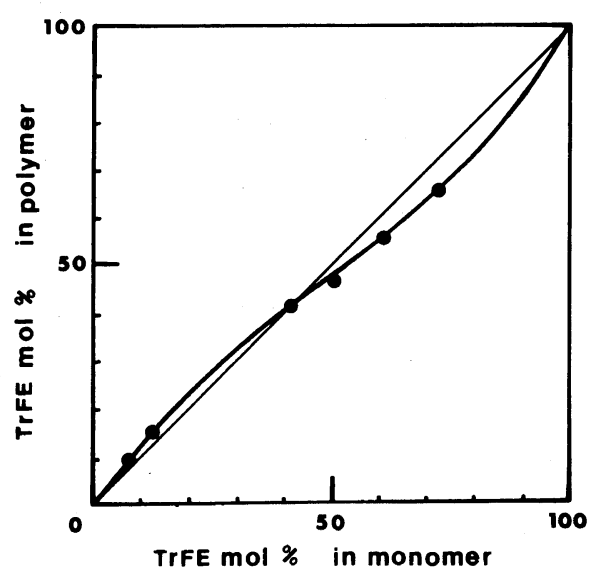

Figure 1. Monomer-polymer composition diagram of vinylidene fluoride (VDF)-trifluoroethylene (TRFE) system.
$(\mathrm{VDF})=0.7$ and $r_{\mathrm{B}}(\mathrm{TRFE})=0.5$, at $22^{\circ} \mathrm{C}$. It was noticed that in a copolymer the monomers VDF and TRFE are arranged at random along the polymer chain.

\section{Comonomer Sequence Distribution}

Ito and Yamashita ${ }^{27}$ developed a theory to characterize the copolymer composition and microstructure by applying the statistical stationary process given by Coleman and Fox. ${ }^{24}$ They treated three models in a copolymerization system, in which the last one, two, or three monomer units in a propagating polymer radical affect the probability of monomer addition (terminal, penultimate, and penpenultimate models). From these three models we adopted the terminal model to obtain the normalized fraction of monomer diad and triad as a function of polymer composition. For this system the conditional probabilities are

$$
\begin{aligned}
& P_{\mathrm{AA}}=r_{\mathrm{A}} /\left(1+r_{\mathrm{A}} F\right) \\
& P_{\mathrm{AB}}=1 /\left(1+r_{\mathrm{A}} F\right) \\
& P_{\mathrm{BA}}=1 /\left(1+r_{\mathrm{B}} / F\right) \\
& P_{\mathrm{BB}}=\left(r_{\mathrm{B}} / F\right) /\left(1+r_{\mathrm{B}} / F\right)
\end{aligned}
$$

where $r_{\mathrm{A}}$ and $r_{\mathrm{B}}$ are monomer reactivity ratios and $F$ is the ratio of initial monomer fractions. The fractions of monomers $[F(\mathrm{~A})$ and $F(\mathrm{~B})]$ are given by

$$
\begin{aligned}
& F(\mathrm{~A})=P_{\mathrm{BA}} /\left(P_{\mathrm{AB}}+P_{\mathrm{BA}}\right) \\
& F(\mathrm{~B})=P_{\mathrm{AB}} /\left(P_{\mathrm{AB}}+P_{\mathrm{BA}}\right) \\
& F(\mathrm{~A})+F(\mathrm{~B})=1
\end{aligned}
$$

Substitution of eq 1 into eq 2 yields the Mayo-Lewis equation. ${ }^{30}$ The fractions of monomer diads [ $F(\mathrm{AA})$, $F(\mathrm{AB}), F(\mathrm{BA})$, and $F(\mathrm{BB})]$, are given by

$$
\begin{aligned}
& F(\mathrm{AA})=P_{\mathrm{BA}} P_{\mathrm{AA}} /\left(P_{\mathrm{AB}}+P_{\mathrm{BA}}\right) \\
& F(\mathrm{AB})=F(\mathrm{BA})=P_{\mathrm{BB}} P_{\mathrm{BA}} /\left(P_{\mathrm{AB}}+P_{\mathrm{BA}}\right) \\
& F(\mathrm{BB})=P_{\mathrm{AB}} P_{\mathrm{BB}} /\left(P_{\mathrm{AB}}+P_{\mathrm{BA}}\right) \\
& F(\mathrm{AA})+F(\mathrm{AB})+F(\mathrm{BA})+F(\mathrm{BB})=1
\end{aligned}
$$

The fractions of monomer triads [ $F(\mathrm{AAA}), F(\mathrm{AAB})$, $F(\mathrm{ABA}), F(\mathrm{ABB}), F(\mathrm{BAA}), F(\mathrm{BAB}), F(\mathrm{BBA})$, and $F(\mathrm{BBB})]$ are given by

$$
\begin{aligned}
& F(\mathrm{AAA})=P_{\mathrm{BA}} P_{\mathrm{AA}} P_{\mathrm{AA}} /\left(P_{\mathrm{AB}}+P_{\mathrm{BA}}\right) \\
& F(\mathrm{AAB})=F(\mathrm{BAA})=P_{\mathrm{AB}} P_{\mathrm{AA}} P_{\mathrm{BA}} /\left(P_{\mathrm{AB}}+P_{\mathrm{BA}}\right) \\
& F(\mathrm{ABA})=P_{\mathrm{BA}} P_{\mathrm{BA}} P_{\mathrm{AB}} /\left(P_{\mathrm{AB}}+P_{\mathrm{BA}}\right) \\
& F(\mathrm{BAB})=P_{\mathrm{AB}} P_{\mathrm{AB}} P_{\mathrm{BA}} /\left(P_{\mathrm{AB}}+P_{\mathrm{BA}}\right) \\
& F(\mathrm{BBA})=F(\mathrm{ABB})=P_{\mathrm{AB}} P_{\mathrm{BA}} P_{\mathrm{BB}} /\left(P_{\mathrm{AB}}+P_{\mathrm{BA}}\right) \\
& F(\mathrm{BBB})=P_{\mathrm{AB}} P_{\mathrm{BB}} P_{\mathrm{BB}} /\left(P_{\mathrm{AB}}+P_{\mathrm{BA}}\right) \\
& F_{\mathrm{AAA}}+F_{\mathrm{AAB}}+F_{\mathrm{ABA}}+F_{\mathrm{ABB}}+F_{\mathrm{BAA}} \\
& \quad+F_{\mathrm{BAB}}+F_{\mathrm{BBA}}+F_{\mathrm{BBB}}=1
\end{aligned}
$$




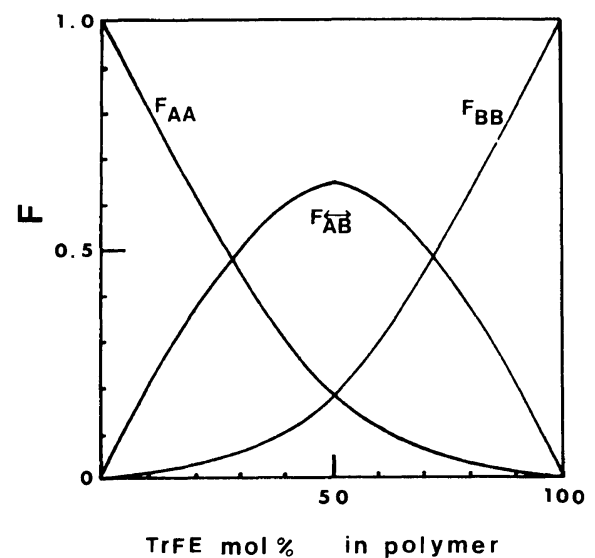

Figure 2. Normalized fractions of monomer diad as a function of polymer composition for VDF-TRFE copolymers. $F(\overleftrightarrow{\mathrm{AB}})$ means $F(\mathrm{AB})+F(\mathrm{BA})$

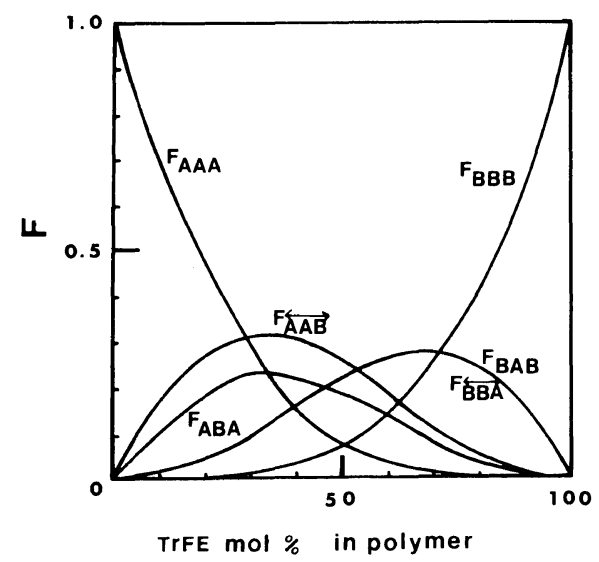

Figure 3. Normalized fractions of monomer triad as a function of polymer composition for VDF-TRFE copolymers. $F(\overleftrightarrow{\mathrm{AAB}})$, and $F(\overleftrightarrow{\mathrm{BBA}})$ mean $F(\mathrm{AAB})+F(\mathrm{BAA})$, and $F(\mathrm{BBA})+F(\mathrm{ABB})$, respectively.

Figures 2 and 3 show the normalized fractions of monomer diad and triad as a function of polymer composition. In the figure, $F(\overleftrightarrow{\mathrm{AB}}), F(\overleftrightarrow{\mathrm{AAB}})$, and $F(\overleftrightarrow{\mathrm{BBA}})$ mean $F(\mathrm{AB})+F(\mathrm{BA}), F(\mathrm{AAB})+F(\mathrm{BAA})$ and $F(\mathrm{BBA})+F(\mathrm{ABB})$, respectively. It may be expected that the randomness of monomer distribution in copolymer chain will be most remarkable at the 50:50 VDF-TRFE polymer composition.

\section{NMR Assignment}

Figures 4 and 5 show the ${ }^{19} \mathrm{~F}$ NMR spectra of

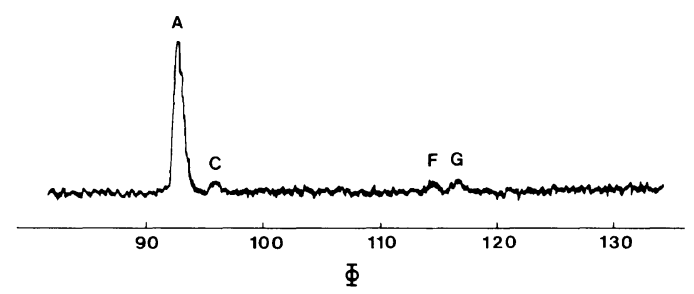

Figure 4. ${ }^{19} \mathrm{~F}$ NMR spectrum of sample A1 (PVDF) in $-\mathrm{CF}_{2}-$ region at $56.45 \mathrm{MHz}$ and $35^{\circ} \mathrm{C}$ in dimethylformamide. Benzotrifluoride internal reference.

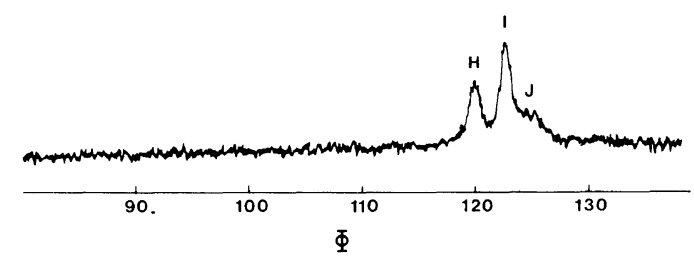

Figure 5. ${ }^{19} \mathrm{~F}$ NMR spectrum of sample A7 (PTRFE) in $-\mathrm{CF}_{2}-$ region at $56.45 \mathrm{MHz}$ and $35^{\circ} \mathrm{C}$ in acetone. Benzotrifluoride internal reference.

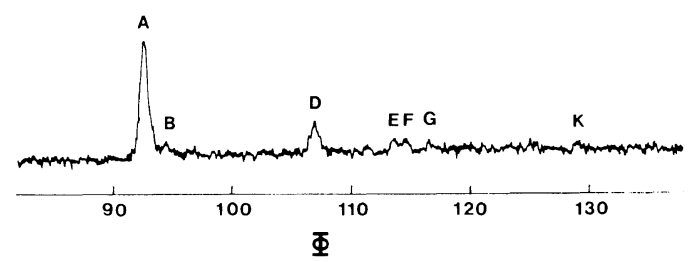

Figure 6. ${ }^{19} \mathrm{~F}$ NMR spectrum of sample A2 (VDF-TRFE $90: 10$ ) in $-\mathrm{CF}_{2}$ - region at $56.45 \mathrm{MHz}$ and $35^{\circ} \mathrm{C}$ in acetone. Benzotrifluoride internal reference.

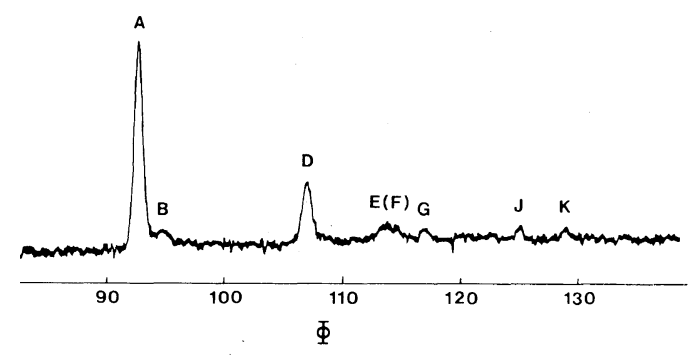

Figure 7. ${ }^{19} \mathrm{~F}$ NMR spectrum of sample A3 (VDF-TRFE $85: 15$ ) in $-\mathrm{CF}_{2}$ - region at $56.45 \mathrm{MHz}$ and $35^{\circ} \mathrm{C}$ in acetone. Benzotrifluoride internal reference.

homopolymers in $-\mathrm{CF}_{2}-$ region. Figures 6 and 7 show those of VDF-rich copolymers in $-\mathrm{CF}_{2}-$ region. Figure 8 shows those of approximately $1: 1$ 


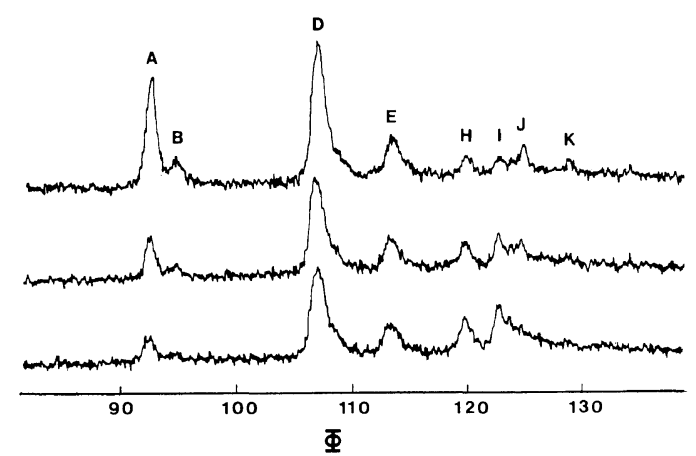

Figure 8. ${ }^{19} \mathrm{~F}$ NMR spectra of samples $\mathrm{A} 4, \mathrm{~A} 5$, and $\mathrm{A} 6$ (VDF-TRFE $60: 40,45: 55$, and $36: 64$ ) in $-\mathrm{CF}_{2}-$ region at $56.45 \mathrm{MHz}$ and $35^{\circ} \mathrm{C}$ in acetone. Benzotrifluoride internal reference.

Table II. Microstructures of carbon pentad sequences with a $-\mathrm{CF}_{2}-$ group at their centers

\begin{tabular}{|c|c|}
\hline Structure no. & Structure \\
\hline st. (1) & $-\mathrm{CF}_{2}-\mathrm{CH}_{2}-\mathrm{CF}_{2}-\mathrm{CH}_{2}-\mathrm{CF}_{2}-$ \\
\hline st. (2) & $-\mathrm{CH}_{2}-\mathrm{CH}_{2}-\mathrm{CF}_{2}-\mathrm{CH}_{2}-\mathrm{CF}_{2}-$ \\
\hline st. (3) & $-\mathrm{CF}_{2}-\mathrm{CH}_{2}-\mathrm{CF}_{2}-\mathrm{CF}_{2}-\mathrm{CH}_{2}-$ \\
\hline st. (4) & $-\mathrm{CH}_{2}-\mathrm{CH}_{2}-\mathrm{CF}_{2}-\mathrm{CF}_{2}-\mathrm{CH}_{2}-$ \\
\hline st. (5) & $-\mathrm{CF}_{2}-\mathrm{CFH}-\mathrm{CF}_{2}-\mathrm{CFH}-\mathrm{CF}_{2}-$ \\
\hline st. (6) & $-\mathrm{CFH}-\mathrm{CFH}-\mathrm{CF}_{2}-\mathrm{CFH}-\mathrm{CF}_{2}-$ \\
\hline st. (7) & $-\mathrm{CF}_{2}-\mathrm{CFH}-\mathrm{CF}_{2}-\mathrm{CF}_{2}-\mathrm{CFH}-$ \\
\hline st. (8) & $-\mathrm{CFH}-\mathrm{CFH}-\mathrm{CF}_{2}-\mathrm{CF}_{2}-\mathrm{CFH}-$ \\
\hline st. (9) & $-\mathrm{CH}_{2}-\mathrm{CFH}-\mathrm{CF}_{2}-\mathrm{CF}_{2}-\mathrm{CFH}-$ \\
\hline st. (10) & $-\mathrm{CH}_{2}-\mathrm{CFH}-\mathrm{CF}_{2}-\mathrm{CFH}-\mathrm{CF}_{2}-$ \\
\hline st. (11) & $-\mathrm{CFH}-\mathrm{CH}_{2}-\mathrm{CF}_{2}-\mathrm{CH}_{2}-\mathrm{CF}_{2}-$ \\
\hline st. (12) & $-\mathrm{CFH}-\mathrm{CH}_{2}-\mathrm{CF}_{2}-\mathrm{CF}_{2}-\mathrm{CH}_{2}-$ \\
\hline st. (13) & $-\mathrm{CH}_{2}-\mathrm{CH}_{2}-\mathrm{CF}_{2}-\mathrm{CFH}-\mathrm{CF}_{2}-$ \\
\hline st. (14) & $-\mathrm{CFH}-\mathrm{CH}_{2}-\mathrm{CF}_{2}-\mathrm{CFH}-\mathrm{CF}_{2}-$ \\
\hline st. (15) & $-\mathrm{CF}_{2}-\mathrm{CH}_{2}-\mathrm{CF}_{2}-\mathrm{CFH}-\mathrm{CF}_{2}-$ \\
\hline st. (16) & $-\mathrm{CH}_{2}-\mathrm{CH}_{2}-\mathrm{CF}_{2}-\mathrm{CF}_{2}-\mathrm{CFH}-$ \\
\hline st. (17) & $-\mathrm{CFH}-\mathrm{CH}_{2}-\mathrm{CF}_{2}-\mathrm{CF}_{2}-\mathrm{CFH}-$ \\
\hline st. (18) & $-\mathrm{CF}_{2}-\mathrm{CH}_{2}-\mathrm{CF}_{2}-\mathrm{CF}_{2}-\mathrm{CFH}-$ \\
\hline st. (19) & $-\mathrm{CH}_{2}-\mathrm{CFH}-\mathrm{CF}_{2}-\mathrm{CH}_{2}-\mathrm{CF}_{2}-$ \\
\hline st. $(20)$ & $-\mathrm{CFH}-\mathrm{CFH}-\mathrm{CF}_{2}-\mathrm{CH}_{2}-\mathrm{CF}_{2}-$ \\
\hline st. (21) & $-\mathrm{CH}_{2}-\mathrm{CFH}-\mathrm{CF}_{2}-\mathrm{CF}_{2}-\mathrm{CH}_{2}-$ \\
\hline st. (22) & $-\mathrm{CFH}-\mathrm{CFH}-\mathrm{CF}_{2}-\mathrm{CF}_{2}-\mathrm{CH}_{2}-$ \\
\hline st. (23) & $-\mathrm{CF}_{2}-\mathrm{CFH}-\mathrm{CF}_{2}-\mathrm{CF}_{2}-\mathrm{CH}_{2}-$ \\
\hline
\end{tabular}

VDF-TRFE copolymers in $-\mathrm{CF}_{2}-$ region. The main resonance peaks are designated as $\mathrm{A}, \mathrm{B}, \mathrm{C}, \mathrm{D}, \mathrm{E}, \mathrm{F}$, $\mathrm{G}, \mathrm{H}, \mathrm{I}, \mathrm{J}$, and $\mathrm{K}$ (in the order of increasing magnetic field). The peaks which appeared at the same position in those spectra are denoted by the same letter. The magnetic-field scale is given in parts per million (ppm). BTF was used as the internal reference. The chemical shifts are expressed by the addition of 63.7 $\mathrm{ppm}$ to each original value.

There are 23 microstructures of carbon-pentad sequence which have a $-\mathrm{CF}_{2}$ - group at the center in the VDF-TRFE-copolymers system, as shown in Table II. If all these structures actually exist in the copolymer sequence, then 23 peaks corresponding to them will be observed in spectra. But, only 11 peaks were observed in the spectra, so it is conceivable that some of the structures shown in Table II do not actually exist in the copolymer and/or some of the 23 peaks overlap each other.

Comparing the NMR spectra of VDF-TRFE copolymers, peaks $\mathrm{A}, \mathrm{C}, \mathrm{F}, \mathrm{G}, \mathrm{H}, \mathrm{I}$, and $\mathrm{J}$ are derived from both PVDF (sample A1) and PTRFE (sample A7), while peaks $\mathrm{B}, \mathrm{D}, \mathrm{E}$, and $\mathrm{K}$ are characteristic of VDF-TRFE copolymer sequences.

We take the following factors into account in making the spectral assignment.

(1) The experimental law ${ }^{2,4}$ of ${ }^{19} \mathrm{~F}$ NMR that the chemical shifts of the central $-\mathrm{CF}_{2}-$ group are affected when the first or second neighbor is substituted by $-\mathrm{CFH}-$ or $-\mathrm{CF}_{2}-\left(\right.$ from $\left.-\mathrm{CH}_{2}-\right)$. If the first neighbor is $-\mathrm{CF}_{2}-$, then the central $-\mathrm{CF}_{2}-$ peak shift upfield by $9.5 \mathrm{ppm}$, independently of other groups. On the other hand, substitution of a second group by $-\mathrm{CF}_{2}-$ shifts the central $-\mathrm{CF}_{2}-$ peak downfield by $2.5 \mathrm{ppm}$, again independently of other groups.

(2) ${ }^{19}$ F NMR studies ${ }^{1-4}$ of fluorinated homopolymers and copolymers.

Supposing that $\mathrm{CH}_{2}$ is the tail and $\mathrm{CF}_{2}$ is the head in VDF, and that $\mathrm{CFH}$ is the tail and $\mathrm{CF}_{2}$ is the head in TRFE, we represent forward addition, which is defined as the addition of a monomer at the tail position to any propagating radical, by the symbol $(\mathrm{N})$, and the backward addition, which is defined as the addition of a monomer at the head position to a propagating radical, by the symbol (B).

Sample A1. The ${ }^{19} \mathrm{~F}$ NMR spectrum of PVDF in $-\mathrm{CF}_{2}-$ region is shown in Figure 4. The detailed work of Wilson ${ }^{3,4}$ showed that the peaks observed in PVDF were associated with structures st. (1), (2), (3), and (4) in Table II. The chemical shifts and carbonpentad structures are listed in Table III.

Sample A7. The ${ }^{19} \mathrm{~F}$ NMR spectrum of PTRFE in $-\mathrm{CF}_{2}-$ region is shown in Figure 5. We assigned peaks $\mathrm{H}, \mathrm{I}$, and $\mathrm{J}$ as follows. Peak $\mathrm{H}$ corresponds to st. (5), peak I corresponds to st. (6) and (7), and peak J corresponds to st. (8) in Table II. The detail 
Table III. Chemical shift assignment of ${ }^{19} \mathrm{~F}$ NMR peaks of VDF-TRFE copolymers

\begin{tabular}{|c|c|c|}
\hline Peak & $\begin{array}{l}\text { Chemical shift, } \\
\text { ppm }\end{array}$ & Structure \\
\hline A & 92.7 & $-\mathrm{CF}_{2}-\mathrm{CH}_{2}-\mathrm{CF}_{2}-\mathrm{CH}_{2}-\mathrm{CF}_{2}-$ \\
\hline B & 94.8 & $-\mathrm{CFH}-\mathrm{CH}_{2}-\mathrm{CF}_{2}-\mathrm{CH}_{2}-\mathrm{CF}_{2}-$ \\
\hline $\mathrm{C}$ & 95.9 & $-\mathrm{CH}_{2}-\mathrm{CH}_{2}-\mathrm{CF}_{2}-\mathrm{CH}_{2}-\mathrm{CF}_{2}-$ \\
\hline $\mathrm{D}$ & 107.1 & $-\mathrm{CF}_{2}-\mathrm{CFH}-\mathrm{CF}_{2}-\mathrm{CH}_{2}-\mathrm{CF}_{2}-$ \\
\hline $\mathrm{E}$ & 113.4 & $-\mathrm{CF}_{2}-\mathrm{CH}_{2}-\mathrm{CF}_{2}-\mathrm{CF}_{2}-\mathrm{CFH}-$ \\
\hline $\mathrm{F}$ & 114.7 & $-\mathrm{CF}_{2}-\mathrm{CH}_{2}-\mathrm{CF}_{2}-\mathrm{CF}_{2}-\mathrm{CH}_{2}-$ \\
\hline G & 117.0 & $-\mathrm{CH}_{2}-\mathrm{CH}_{2}-\mathrm{CF}_{2}-\mathrm{CF}_{2}-\mathrm{CH}_{2}-$ \\
\hline $\mathrm{H}$ & 119.6 & $-\mathrm{CF}_{2}-\mathrm{CFH}-\mathrm{CF}_{2}-\mathrm{CFH}-\mathrm{CF}_{2}-$ \\
\hline I & 122.7 & $\begin{array}{l}-\mathrm{CFH}-\mathrm{CFH}-\mathrm{CF}_{2}-\mathrm{CFH}-\mathrm{CF}_{2}- \\
-\mathrm{CF}_{2}-\mathrm{CFH}-\mathrm{CF}_{2}-\mathrm{CF}_{2}-\mathrm{CFH}-\end{array}$ \\
\hline $\mathbf{J}$ & 125.9 & $\begin{array}{l}-\mathrm{CFH}-\mathrm{CF}_{2}-\mathrm{CF}_{2}-\mathrm{CFH}-\mathrm{CFH}- \\
-\mathrm{CH}_{2}-\mathrm{CF}_{2}-\mathrm{CF}_{2}-\mathrm{CFH}-\mathrm{CF}_{2}-\end{array}$ \\
\hline $\mathrm{K}$ & 128.8 & $-\mathrm{CH}_{2}-\mathrm{CF}_{2}-\mathrm{CF}_{2}-\mathrm{CFH}-\mathrm{CH}_{2}-$ \\
\hline
\end{tabular}

process of assigment was reported elsewhere. ${ }^{15}$ The results are listed in Table III.

Sample A2. The ${ }^{19}$ F NMR spectrum of $90: 10$ VDF-TRFE in $-\mathrm{CF}_{2}-$ region is shown in Figure 6. As the content of TRFE monomer is only $10 \mathrm{~mol}^{\circ} \%$, the microstructure of sample A2 is thought to resemble that of PVDF. In the spectrum, seven peaks (A, B, D, E, F, G, and K) are observed. Among these peaks, peaks $A, B, F$, and $G$ surely correspond to those of PVDF. But, the chemical shift of peak B is $94.8 \mathrm{ppm}$, which is slightly different from peak C. The chemical shift of peak $C(95.9 \mathrm{ppm})$ accurately corresponds to st. (2) in Table II. We will consider the reason for this difference between the chemical shifts of peaks B and C later. Peaks D, F, and $\mathrm{K}$ surely originated from the VDF-TRFE copolymer sequence. Among these peaks, peak D is very large.

We made the following assumptions in order to assign these new peaks to the microstructure of sample A2.

(1) There is no TRFE-TRFE sequence, i.e., only one TRFE monomer exists in the monomertriad sequence. This assumption is justifed by the normalized monomer-diad and -triad sequence distributions shown in Figures 2 and 3.

(2) The end of last VDF monomer of the propagating radical to which a TRFE monomer attaches is usually in the head position.

(3) There is $7 \%$ of backward added VDF monomers in the long sequence of VDF monomers, in the same manner as found for PVDF molecules. ${ }^{3}$

(4) When the last monomer of the propagating
Table IV. Reactivity ratio of $\mathrm{CH}_{2}$ position to $\mathrm{CF}_{2}$ position of VDF $\left(\mathrm{CH}_{2}=\mathrm{CF}_{2}\right)$ onto radical. These are reproduced from the data by Tedder and coworkers ${ }^{31,32}$

\begin{tabular}{rc}
\hline Radical & Reactivity ratio \\
\hline $\mathrm{CH}_{3} \cdot$ & $1 / 0.179$ \\
$\mathrm{CFH}_{2} \cdot$ & $1 / 0.44$ \\
$\mathrm{CF}_{2} \mathrm{H} \cdot$ & $1 / 0.15$ \\
$\mathrm{CF}_{3} \cdot$ & $1 / 0.03$ \\
$\mathrm{C}_{3} \mathrm{~F}_{7} \cdot$ & $1 / 0.009$ \\
\hline
\end{tabular}

radical is TRFE, then the VDF monomer is ordinarily added to this radical from the tail position. This assumption is justified by the fact that the VDF monomer has a tendency to add radicals from the tail position independent of radical species. Table IV shows the reactivity ratio of $\mathrm{CH}_{2}$ to $\mathrm{CF}_{2}$ of VDF monomer onto the radical. ${ }^{31,32}$

The above assumption leads to the following polymer segment.

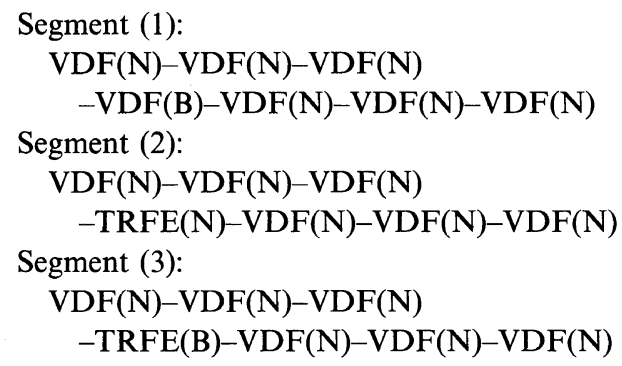

Segment (1) contains one backward added VDF monomer in the sequence. Segment (2) contains one forward added TRFE monomer in the $\operatorname{VDF}(\mathrm{N})$ sequence. Segment (3) contains one backward added TRFE monomer in the $\operatorname{VDF}(\mathrm{N})$ sequence. The microstructure of segment (1) is the same as that of PVDF.

The microstructure of segment (2) is

$$
\begin{gathered}
-\mathrm{CH}_{2}-\mathrm{CF}_{2}-\mathrm{CH}_{2}-\mathrm{CF}_{2}-\mathrm{CH}_{2}-\mathrm{CH}_{2}-\mathrm{CFH}-\mathrm{CH}_{2}^{3} \\
-\mathrm{CH}_{2}-\mathrm{CF}_{2}-\mathrm{CH}_{2}-\mathrm{CF}_{2}-\mathrm{CH}_{2}-\mathrm{CF}_{2}-
\end{gathered}
$$

Carbon-pentad structures with a central $-\mathrm{CF}_{2}-$ group are as follows.

$$
\begin{aligned}
& \text { from } 1,4,5 \\
& \quad-\mathrm{CF}_{2}-\mathrm{CH}_{2}-\mathrm{CF}_{2}-\mathrm{CH}_{2}-\mathrm{CF}_{2}- \\
& \text { from } 2,3 \\
& \quad-\mathrm{CF}_{2}-\mathrm{CH}_{2}-\mathrm{CF}_{2}-\mathrm{CFH}-\mathrm{CF}_{2}-
\end{aligned}
$$


The microstructure of segment (3) is

$$
\begin{gathered}
-\mathrm{CH}_{2}-\mathrm{CF}_{2}-\mathrm{CH}_{2}-\mathrm{CF}_{2}-\mathrm{CH}_{2}-\mathrm{CF}_{2}-\mathrm{CF}_{2}-\mathrm{CFH} \\
-\mathrm{CH}_{2}-\mathrm{CF}_{2}-\mathrm{CH}_{2}-\mathrm{CF}_{2}-\mathrm{CH}_{2}-\mathrm{CF}_{2}-
\end{gathered}
$$

Carbon-pentad structures with a central $-\mathrm{CF}_{2}-$ group are as follows.

$\begin{array}{llr}\text { from 6, } 10-\mathrm{CF}_{2}-\mathrm{CH}_{2}-\mathrm{CF}_{2}-\mathrm{CH}_{2}-\mathrm{CF}_{2}- & \text { st. (1) } \\ \text { from 7 } & -\mathrm{CF}_{2}-\mathrm{CH}_{2}-\mathrm{CF}_{2}-\mathrm{CH}_{2}-\mathrm{CFH}_{-} \text {st. (18) } \\ \text { from 8 } & -\mathrm{CH}_{2}-\mathrm{CF}_{2}-\mathrm{CF}_{2}-\mathrm{CFH}_{-} \mathrm{CH}_{2}-\text { st. (21) } \\ \text { from 9 } & -\mathrm{CFH}_{-}-\mathrm{CH}_{2}-\mathrm{CF}_{2}-\mathrm{CH}_{2}-\mathrm{CF}_{2}-\text { st. (11) }\end{array}$

Structures (15), (18), (21), and (11) appear only in sample A2, not in PVDF. These four structures seem to correspond to four peaks $\mathrm{B}, \mathrm{D}, \mathrm{E}$, and $\mathrm{K}$.

Judging from the experimental law of ${ }^{19} \mathrm{~F}$ NMR, the chemical shift of st. (11) is at the center of the shifts of st. (1) and (2). As there is no clear peak at 95.9 ppm for st. (2), it is certainly possible to consider that peak B is coupling with peak C. Peak B thus corresponds to st. (11). The real chemical shift position of st. (11) must be on the slightly downfield side of $94.8 \mathrm{ppm}$.

Judging from the ${ }^{19} \mathrm{~F}$ NMR experimental law, the chemical shift of st. (21) must be on the upfield side of the shifts of st. (8). The peak for st. (8) is $125.9 \mathrm{ppm}$; it was named peak $\mathbf{J}$. There is only one peak (peak $\mathrm{K}$ ) on the upfield side of peak $\mathbf{J}$. Thus this peak $\mathrm{K}$ observed at $128.8 \mathrm{ppm}$ coreresponds to st. (21).

The st. (18) resembles st. (3). Judging from the experimental law, the chemical shift of st. (18) is a little downfield of peak F. Peak E is at 113.4 ppm, where two peaks (peak E and F) are slightly overlapping. Peak E definitely corresponds to st. (18).

In the same manner, using the experimental law, st. (15) must be upfield of st. (2) and downfield of st. (18). Only peak D can correspond to st. (15). Structure (15) must be observed as peak $D$ in the ${ }^{19} \mathrm{~F}$ NMR spectrum.

From the assumptions for the microstructure of sample A2, it is expected that the amounts of st. (2), (3), and (4) will be equal. Furthermore, st. (11), (18), and (21) must be present in equal amounts. Comparing the fractions of these structures in NMR spectrum, it was found that they agreed well. This result indicates the correctness of the chemical shifts assignments to peak $\mathrm{B}, \mathrm{D}, \mathrm{E}$, and $\mathrm{K}$. The results are listed in Table III.

Sample A3. The ${ }^{19} \mathrm{~F}$ NMR spectrum of $85: 15$ VDF-TRFE in $-\mathrm{CF}_{2}-$ region is shown in Figure 5.
The microstructure of sample $\dot{A} 3$ is thought to resemble that of sample A2. Only peak $J$ is new in the NMR spectrum of sample A3 as compared with that of sample A2. Peak $J$ is observed at $125.9 \mathrm{ppm}$ and appears at the same position as st. (8). Structure (8) results from a TRFE-TRFE-TRFE sequence of PTRFE homopolymer. As is obvious from the copolymer composition, which is shown in Figure 3, the amount of TRFE-TRFE-TRFE sequence in sample A3 is not great. The content of TRFE in sample A3 is only $15 \mathrm{~mol} \%$ and the fraction of TRFE-TRFE-TRFE sequence is 0 . Therefore, it is hard to consider that peak $J$ corresponds to st. (8). Furthermore, if st. (8) actually exists in sample A3, then peaks of st. (6) and (7) must be observed in the NMR spectrum along with the peak of st. (8). But, there are no such peaks in NMR spectrum, as is seen in Figure 5. So we judged that the peak $\mathbf{J}$ is not derived from st. (8) but from a structure whose microstructure is similar to st. (8). From Table II, we can select st. (23) as the most likely structure for peak J. Structure (23) can be derived from VDF (N)-TRFE(B)-VDF(B) or VDF(N)-TRFE(B)TRFE(B) sequence. The fraction of VDFTRFE-VDF is 0.13 , while that of VDF-TRFETRFE is 0 (see Figure 3). So peak $J$ surely derives from the VDF-TRFE-VDF sequence.

Applying the assumption used for the polymer segment of sample A2, the polymer segment which newly appeared in sample A3 can be described as follows.

Segment (4):

$\operatorname{VDF}(\mathrm{N})-\operatorname{VDF}(\mathrm{N})-\operatorname{VDF}(\mathrm{N})-\mathrm{TRFE}(\mathrm{B})$

$$
-\mathrm{VDF}(\mathrm{B})-\mathrm{VDF}(\mathrm{N})-\mathrm{VDF}(\mathrm{N})
$$

The microstructure of segment (4) is

$$
\begin{aligned}
& -\mathrm{CH}_{2}-\mathrm{CF}_{2}-\mathrm{CH}_{2}-\mathrm{CF}_{2}-\mathrm{CH}_{2}-\mathrm{CF}_{2}-\mathrm{CFH} \\
& -\mathrm{CF}_{2}-\mathrm{CF}_{2}-\mathrm{CH}_{2}-\mathrm{CH}_{2}-\mathrm{CF}_{2} \\
& -\mathrm{CH}_{2}-\mathrm{CF}_{2}-
\end{aligned}
$$

Carbon-pentad structures with a central $-\mathrm{CF}_{2}-$ group are as follows.

$$
\begin{array}{llr}
\text { from 11 } & -\mathrm{CF}_{2}-\mathrm{CH}_{2}-\mathrm{CF}_{2}-\mathrm{CH}_{2}-\mathrm{CF}_{2}- & \text { st. (1) } \\
\text { from 12 } & -\mathrm{CF}_{2}-\mathrm{CH}_{2}-\mathrm{CF}_{2}-\mathrm{CF}_{2}-\mathrm{CFH}- & \text { st. (18) } \\
\text { from 13 } & -\mathrm{CF}_{2}-\mathrm{CFH}_{-}-\mathrm{CF}_{2}-\mathrm{CF}_{2}-\mathrm{CH}_{2}- & \text { st. (23) } \\
\text { from 14 } & -\mathrm{CH}_{2}-\mathrm{CH}_{2}-\mathrm{CF}_{2}-\mathrm{CFH}_{-}-\mathrm{CF}_{2}- & \text { st. (13) } \\
\text { from 15 } & -\mathrm{CH}_{2}-\mathrm{CH}_{2}-\mathrm{CF}_{2}-\mathrm{CH}_{2}-\mathrm{CF}_{2}- & \text { st. (2) }
\end{array}
$$

If st. (23) really exists in the $85: 15 \mathrm{VDF}-\mathrm{TRFE}$ 
copolymer chain, then st. (2), (13), and (18) must give NMR signal in the same manner as st. (23). Among these four structures, st. (2) and (18) are observed as peaks B and E, respectively. And st. (13) is observed as the shoulder of peak D at $109.1 \mathrm{ppm}$. Comparing intensity ratios of these peaks, it was found that they agree well. Thus, we judged that peak $\mathrm{J}$ corresponded to st. (23).

Sample A4, A5, and A6. Figure 6 shows the ${ }^{19} \mathrm{~F}$ NMR spectra of samples A4, A5, and A6 in $-\mathrm{CF}_{2}-$ region. The molar ratios of these copolymers are close to unity. The NMR spectra of these copolymers resemble one another. There are 8 peaks $(\mathrm{A}, \mathrm{B}, \mathrm{D}, \mathrm{E}$, $\mathrm{F}, \mathrm{G}, \mathrm{H}, \mathrm{I}, \mathrm{J}$, and $\mathrm{K}$ ) in the spectra of these three samples. These peaks were already observed in samples A1, A2, A3, and A7, and were assigned as listed in Table III. As noted above, these assignments are based on only the limited polymer segments of samples A1, A2, A3, and A7 [segments (1), (2), (3), and (4)]. The existence of other carbon-pentad structures having $-\mathrm{CF}_{2}-$ group at their centers can be presumed in samples A4, A5, and A6, because the VDF-TRFE copolymer systems have a random configuration and the existence of the 23 kinds of structures listed in Table II can be presumed. We have judged that the structures which are not apparent in the NMR spectrum are very minor and practically do not exist in the copolymer chain.

The main feature of the spectra of these copolymers is peak D. Peak D is assigned to st. (15): this microstructure is derived from $\operatorname{VDF}(\mathrm{N})$ $\operatorname{VDF}(\mathrm{N})-\operatorname{TRFE}(\mathrm{N}), \operatorname{VDF}(\mathrm{N})-\operatorname{TRFE}(\mathrm{N})-\operatorname{VDF}(\mathrm{N})$, $\operatorname{TRFE}(\mathrm{N})-\operatorname{TRFE}(\mathrm{N})-\mathrm{VDF}(\mathrm{N})$, and $\operatorname{TRFE}(\mathrm{N})-$ $\operatorname{VDF}(\mathrm{N})$-TRFE(N). These 4 monomer-triad sequences consist of head-to-tail structures of VDF-TRFE or TRFE-VDF sequences. As described above, we studied the ${ }^{19} \mathrm{~F}$ NMR spectra of VDF-TRFE copolymers. The chemical shifts and assignment of the peaks observed in the spectra are summarized in Table III.

\section{Monomer-Sequence Distribution}

The monomer-diad fractions as a function of polymer composition are shown by solid lines in Figure 9. These data are calculated by simply determining the ratios of the integrated intensities of the respective peaks in NMR spectra. It may be expected from the figure that the VDF-TRFE copolymer systems are in random configuration. The broken lines in Figure 9 are calculated by eq 1, 2, and

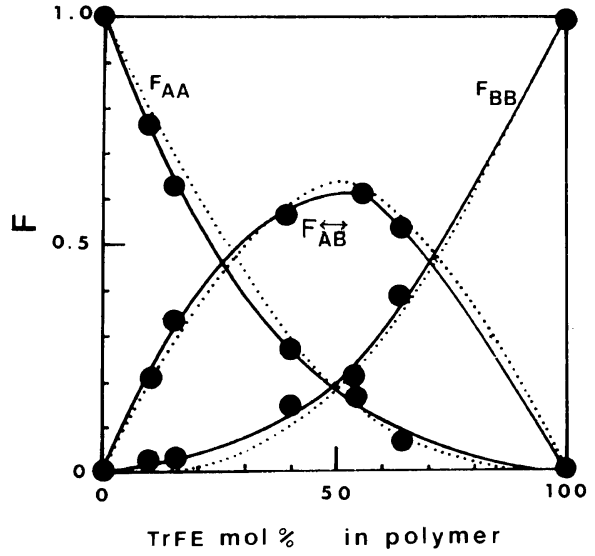

Figure 9. Normalized fractions of monomer diad as a function of polymer coposition for the VDF-TRFE system: (-), calculated by simply measuring the ratios of the integral intensities of the respective peaks; $(\cdots \cdots)$, calculated by eq 1, 2, and 3. Symbols A and B represent VDF and TRFE, respectively.

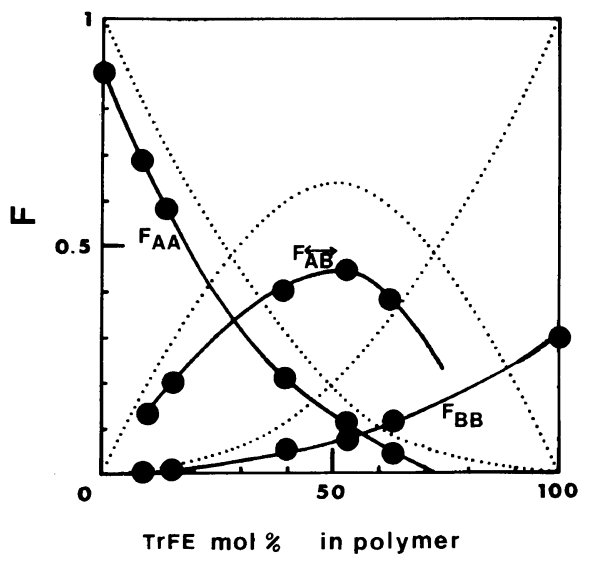

Figure 10. Normalized fractions of monomer diad, consisted of head-to-tail (H-T) structure in VDF-VDF, VDF-TRFE, and TRFE-TRFE sequences, as a function of polymer composition for VDF-TRFE system ( - ) and normalized monomer-diad fractions containing $\mathrm{H}$ $\mathrm{T}, \mathrm{H}-\mathrm{H}, \mathrm{T}-\mathrm{T}$, and T-H structures $(\cdots \cdots)$. These data are calculated by simply measuring the ratios of the integral intensities of the respective peaks. Symbols A and B represent VDF and TRFE, respectively.

3. These results agree well with the experimental curves estimated by NMR data. This fact indicates the accuracy of the monomer reactivity ratios $\left(r_{\mathrm{A}}\right.$ and $\left.r_{\mathrm{B}}\right)$ and of eq 1,2 , and 3.

The normalized fractions of monomer diad, consisting of head-to-tail structure in VDF-VDF, 
VDF-TRFE, and TRFE-TRFE sequences, as a function of polymer coposition are shown in Figure 10 . These are also calculated by simply measuring the ratios of the integrated intensities of respective NMR peaks. The broken lines in the figure represent the monomer-diad sequence distribution curves containing $\mathrm{H}-\mathrm{T}, \mathrm{H}-\mathrm{H}, \mathrm{T}-\mathrm{T}$, and $\mathrm{T}-\mathrm{H}$ sequences. As is seen from the figure that the amount of $\mathrm{H}-\mathrm{T}$ structure in the VDF-VDF sequence is very large, and that in TRFE-TRFE sequence is very small. However, the amount of the H-T structure in VDF-TRFE or TRFE-VDF sequence is rather abundant. This result indicates that the TRFE monomer react to - - $\mathrm{CH}_{2} \mathrm{CF}_{2} \cdot$ propagating radical from the tail position with a considerably high probability. However, such a behavior is considered to be a unique phenomenon. For example, Tedder and coworkers ${ }^{31,32}$ studied the reactivities of TRFE monomer with respect to reacting positions (head or tail position) to methyl radical $\left(\mathrm{CH}_{3} \cdot\right)$ and fluorinated methyl radicals $\left(\mathrm{CFH}_{2} \cdot \mathrm{CF}_{2} \mathrm{H} \cdot\right.$, and $\left.\mathrm{CF}_{3} \cdot\right)$, in the gaseous state at a high temperature, and showed that the regularity of reacting position of TRFE monomer was very low. Ishigure and coworkers ${ }^{14}$ reported the abnormal reactivity of TRFE monomer by a ${ }^{19} \mathrm{~F}$ NMR study of TRFE-isobutylene copolymers. Furthermore, ${ }^{19} \mathrm{~F}$ NMR and simulation studies of PTRFE ${ }^{15}$ indicated that the TRFE monomer seemed to be polymerized in a random state with respect to the reacting position of monomer; i.e., there was no distinct difference between head and tail position in adding reaction.

Acknowledgements. The authors wish to thank Professor A. Nakajima of Kyoto University for his valuable comments and suggestions, and Dr. Y. Kubouchi, Dr. Y. Kometani, and Mr. A. Yamada of Daikin Kogyo Co., Ltd., for their stimulating discussions and encouragement.

\section{REFERENCES}

1. R. E. Naylor, Jr. and S. W. Lasoski, Jr., J. Polym. Sci., 44, 1 (1960).

2. R. C. Freguson, J. Am. Chem. Soc., 82, 2418 (1960).

3. C. W. Wilson, III, J. Polym. Sci., 56, S12 (1962).

4. C. W. Wilson, III and E. R. Santee, Jr., J. Polym. Sci.,
Part C, No. 8, 97 (1965).

5. A. S. Shashkov, F. A. Galil-Ogly, and A. S. Novikov, Vysokomol. Soedin., 8, 267 (1966).

6. D. D. Lawson and J. D. Ingham, J. Polym. Sci., Part $B, 6,181$ (1968).

7. K. Ishigure and Y. Tabata, Macromolecules, 3, 450 (1970).

8. K. Ishigure, Y. Tabata, and K. Oshima, Polym. J., 2, 321 (1971).

9. M. Goerltz, R. Minke, W. Trautverter, and G. Weisgerber, Angew. Makromol. Chem., 29/30, 137 (1973).

10. K. Ishigure, Y. Tabata, and K. Oshima, Macromolecules, 6, 584 (1973).

11. K. Ishigure, Y. Tabata, and K. Oshima, Macromolecules, 8, 177 (1976).

12. K. Ishigure, H. Ohashi, Y. Tabata, and K. Oshima, Macromolecules, 9, 290 (1976).

13. G. Kojima, H. Wachi, K. Ishigure, and Y. Tabata, $J$. Polym. Sci., 14, 1317 (1976).

14. K. Ishigure, H. Ohashi, Y. Tabata, and K. Oshima, Macromolecules, 10, 567 (1977).

15. T. Yagi, Polym. J., 11, 353 (1979).

16. T. Alfrey, Jr. and G. Goldfinger, J. Chem. Phys., 12, 205 (1944).

17. T. Alfrey, Jr. and G. Goldfinger, J. Chem. Phys., 12, 322 (1944).

18. F. T. Wall, J. Am. Chem. Soc., 66, 2050 (1944).

19. E. Merz, T. Alfrey, Jr., and G. Goldfinger, J. Polym. Sci., 1, 75 (1946).

20. G. Goldfinger and T. Kane, J. Polym. Sci., 3, 462 (1948).

21. R. Miller and L. E. Nielsen, J. Polym. Sci., 46, 303 (1960).

22. F. P. Price, J. Chem. Phys., 36, 209 (1962).

23. H. K. Frensdorff and R. Pariser, J. Chem. Phys., 39, 2303 (1963).

24. B. D. Coleman and T. G Fox, J. Polym. Sci., Part A, 1, 3183 (1963).

25. H. J. Harwood and W. M. Rithey, J. Polym. Sci., Part $B, 2,601$ (1964).

26. T. Fueno and J. Furukawa, J. Polym. Sci., Part A, 2, 3681 (1964).

27. K. Ito and Y. Yamashita, J. Polym. Sci., Part A, 3, 2165 (1965).

28. C. W. Pyun, J. Polym. Sci., Part A-2, 8, 1111 (1970).

29. M. Fineman and S. D. Ross, J. Polym. Sci., 5, 259 (1950).

30. F. R. Mayo and F. M. Lewis, J. Am. Chem. Sci., 66, 1594 (1944).

31. J. M. Tedder, J. C. Walton, and K. D. R. Winton, J. Chem. Soc. Sect. D, 1046 (1971).

32. J. P. Sloan, J. M. Tedder, and J. C. Walton, J. Chem. Soc. Perkin, trans 1, 1846 (1975). 